\title{
Neurocysticercosis in cancer patients
}

\author{
Bernardo Cacho-Díaz ${ }^{1 *}$, Nydia A. Lorenzana-Mendoza ${ }^{1}$, Laura G. Mendoza-Olivas ${ }^{1}$, \\ Alberto González-Aguilar², Marta González-Sanz ${ }^{3}$, Alejandro Monroy-Sosa ${ }^{1}$, and Luis A. Herrera-Montaltro ${ }^{4}$ \\ ${ }^{1}$ Neuro-oncology Unit, National Cancer Institute; ${ }^{2}$ Neuro-oncology Unit, National Neurology and Neurosurgery Institute. Mexico City, Mexico; \\ ${ }^{3}$ Specialist Registrar in Infectious Diseases, Guy's and St Thomas's NHS Foundation Trust, London, United Kingdom; ${ }^{4}$ Research Unit, National \\ Cancer Institute, Mexico City, Mexico
}

\begin{abstract}
Introduction: Neurocysticercosis (NC) is considered as a public health problem. Meanwhile, cancer is the second cause of death around the world. The coexistence of both conditions had been scantly reported or studied. Objective: The objective of the study was to investigate and report the presentation of NC in patients with systemic cancer. Methods: Patients with confirmed cancer and NC at a referral center from January 2012 to June 2017 were included. Demographic, clinical, and radiologic findings were presented. Results: Eighteen cancer patients were diagnosed with NC. Within a mean follow̄-up period of 45.2 months, one died from complications directly related to NC, and seven had associated cancer progression. Headache and seizures were the most common symptoms that led to the diagnosis of NC. The number of lesions seen ranged from 1 to 100. Conclusions: The estimated incidence of NC and cancer is not low and should be considered differential diagnosis of brain metastases, especially in developing countries.
\end{abstract}

Key words: Neurocysticercosis. Cancer. Epidemiology. Developing countries.

\section{Neurocisticercosis en pacientes con cáncer}

\section{Resumen}

Introducción: La neurocisticercosis (NCC) es considerada un problema de salud pública. A su vez, el cáncer es la segunda causa de muerte alrededor del mundo. La coexistencia de ambas condiciones ha sido escasamente reportada o estudiada. Objetivo: Investigar y reportar la presentación de NCC en pacientes con cáncer sistémico. Métodos: Se incluyeron pacièntes con cáncer confirmado y NCC vistos de enero de 2012 a junio de 2017 en un centro de referencia oncológico. Se presêtan hallazgos demográficos, clínicos y radiológicos. Resultados: Dieciocho pacientes fueron diagnosticados con NCC. La media de seguimiento fue de 45,2 meses, un paciente falleció por complicaciones directamente relacionadas a NCC y siete falleciëron por progresión de su cáncer. Cefalea y crisis convulsivas fueron los síntomas más comunes que llevaron al diagnóstico de AidCC. El número de lesiones variaron entre 1 a más de 100. Conclusiones: La incidencia estimada de NCC con cáncer no es baja y debe considerarse como un diagnóstico diferencial de metástasis cerebrales, especialmente en países en vías de desarrollo.

Palabras clave: Neurocisticercosis. Cáncer. Epidemiología. Países en vías de desarrollo.

\section{Correspondence:}

*Bernardo Cacho-Díaz Neuro-oncology Unit

Date of reception: 11-06-2019

Mexico City, Mexico

E-mail: bernardocacho@doctor.com creativecommons.org/licenses/by-nc-nd/4.0/)
Date of acceptance: $17-07-2019$

DOI: 10.24875/RMN.19000092
Available online: $04-12-2019$ Rev Mex Neuroci. 2019;20(6):262-265

www.revmexneurociencia.com r the CC BY-NC-ND license (bttp:// Z 


\section{Introduction}

Neurocysticercosis (NC) is caused by the larvae or cysticerci of Taenia solium. One of the most striking features of NC is its heterogeneous clinical picture, which can range from asymptomatic to severe life-threatening neurologic syndromes ${ }^{1}$. The disease severity and clinical manifestations are indicative of infective burden, location, and the host's immune response ${ }^{2}$. In many developing countries, such as in our country, NC is a frequent medical condition, with reported frequencies as high as $9.1 \%{ }^{3}$. The diagnosis of NC is made by neuroimaging techniques with either computer tomography (CT) or magnetic resonance imaging (MRI). Meanwhile, the lifetime probability of having invasive cancer is $39.7 \%$ for men and $37.6 \%$ for women. With an annual death rate of 168.3 per 100,000 population and an approximate cancer incidence of 418-502/100,000 population, cancer is one of the most common causes of mortality and morbidity 4 .

Information concerning NC and cancer is hardly found in medical literature. Some have suggested that the elicited chronic inflammatory reaction, evasive mechanisms, and molecular mimicry capacity of $T$. solium induce immunosuppression, which can be associated with cerebral gliomas ${ }^{1}$ and hematologic malignancies ${ }^{5}$. A postmortem study reported that $21 \%$ of patients with NC had a malignancy ${ }^{6}$, and some have proposed the pathogenic mechanisms ${ }^{7}$. The purpose of this study was to report the presentation of NC in patients with systemic cancer.

\section{Methods}

A database that was prospectively acquired from January 2012 to June 2017 was analyzed. All patients seen by the neuro-oncologic clinic of a referral cancer center (Instituto Nacional de Cancerología, Mexico City) were included. The demographic information, oncologic history, signs and symptoms, treatment, and median overall survival rates were collected. All patients had histopathologic confirmation of their primary cancer. The diagnosis of NC was made by a combination of clinical features and MRI. Active infection was diagnosed with the presence of active cysts in the vesicular, colloidal vesicular, and/or granular nodular stages on MRI. Overall survival was measured from the time of the first neuro-oncologic consultation until death or the last reported visit. The Institutional Ethics and Scientific Investigation Committees approved data acquisition and analysis.

Table 1. General characteristics of patients with NC $\frac{\curvearrowleft}{\circ}$

Patients characteristics

Gender

Female

Male

Primary site of cancer and stage

Breast

I (1)

II (2)

III (2)

Ovarian

NE (2)

IV (1)

Gastrointestinal

III (1)

IV (1)

Urologic

NE (1)

IV (2)

Skin/Melanoma

NE (1)

II (1)

III (1)

Lung

IV (1)

Head and Neck

IV (1)

Systemic metastases other than the CNS

Present

CNS metastases

Absent

Any clinical manifestation

Headache

Seizures

Intracranial hypertension

Visual impairment

Ataxia

Decreased awareness

None

Diagnosis of NC

Before the diagnosis of cancer

(100-140 months)

After the diagnosis of cancer

(2-191 months)

NE: Non-specified

\section{Results}

The general characteristics are presented in table 1. Of the 18 patients included in this study, $13(72 \%)$ were women. The mean age was $61 \pm 15$ years (range, 36 85 years) at the time of cancer diagnosis and $58 \pm$ 15 years (range, 25-84 years) at the time of NC diagnosis. During the study period, no patient developed 
Table 2. Characteristics of NC lesions

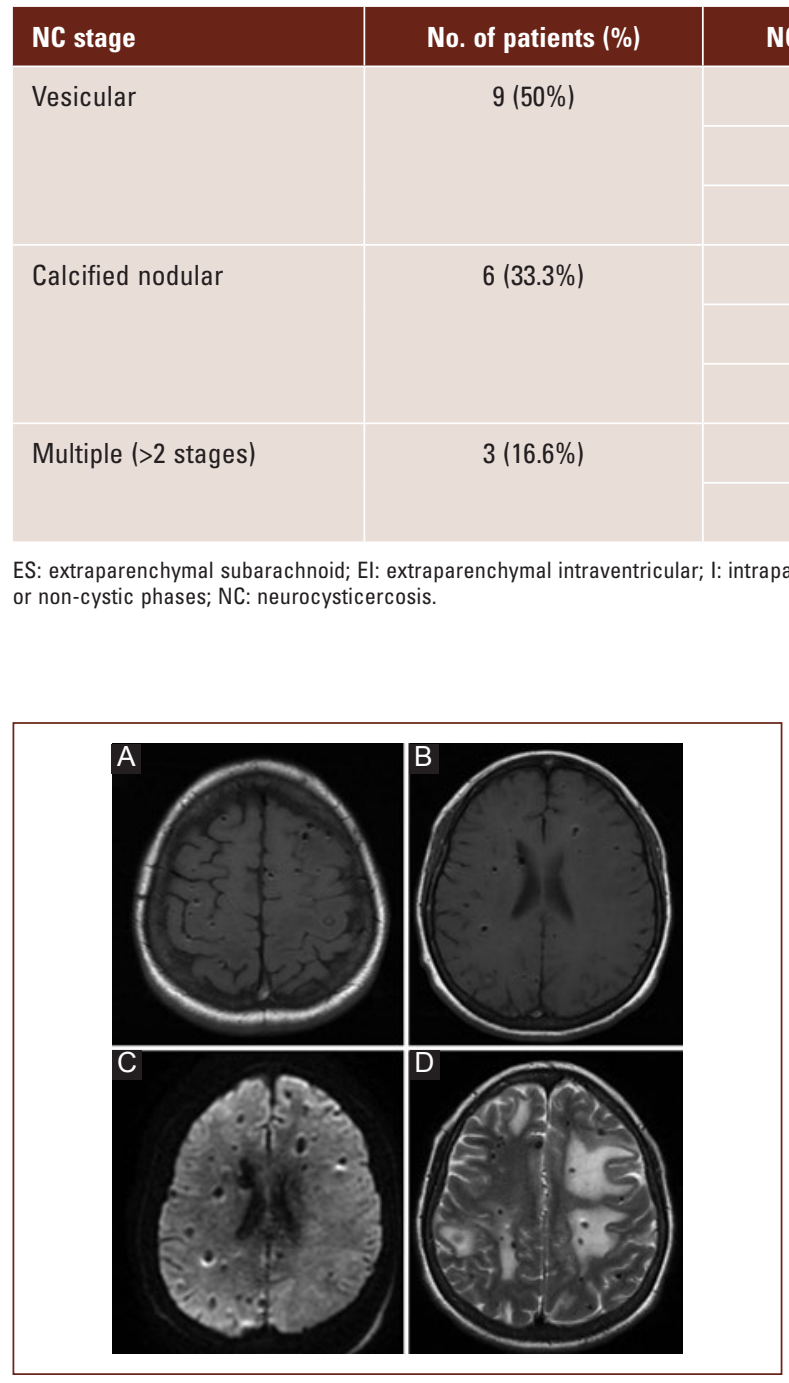

Figure 1. A 61-year-old woman diagnosed with renal carcinoma with metastases to the mediastinum, lung, and suprarenal gland. She presented with seizures and walking impairment, and died 3 months later due to complications of cancer. A and B: Various phases of neurocysticercosis are shown on T1-weighted, C: Diffusion-weighted and D: T2-weighted, imaging sequences on MRI. The lesions resolved after treatment with steroids and albendazole.

Central Nervous System (CNS) metastases, and four patients developed metastases to sites other than the CNS (i.e., mediastinum, bone, lung, and suprarenal gland). The number of lesions seen on MRI was one or two in most patients $(n=13)$ and $\geq 3$ in 5 patients, of which one patient presented with $>100$ lesions.

The characteristics of the NC lesions are presented in table 2. Three patients showed signs of intracranial hypertension; two of them were treated with decompression surgery and, if considered by the neurosurgical team, excision of the intraventricular cysts, and one of them required three surgical interyentions. During a mean follow-up period of 45.2 months (range, 1-147 months), eight deaths were reported, One patient who had a previous history of multiple NC rè̀activations developed NC recurrence and refractory stàtus epilepticus; he died a month after the diagnosis. The other seven deaths were directly related to cancerprogression. The median overall survival was 45 months (95\% Cl 21.7-68.6). Figure 1 illustrates the NCC findings on MRI. All patients with active infection received steroids, followed by albendazole at $15 \mathrm{mg} / \mathrm{kg}$ per day,

\section{Discussion}

T. solium cysticercosis is a globally reemerging disease, with an increasing number of cases in previously considered non-endemic countries, such as the USA, Canăda, Australia, Japan, and Europe ${ }^{8,9}$. We presented 18 patients with NC who concurrently had systemic cancer; majörity comprised women and had a mean age that was similar to that previously reported by others ${ }^{2}$. The most common symptoms that led to the diagnosis were headachecand seizures. During follow-up, one of the patients died from NC-related complications, and seven died because of cancer progression. All patients were initially considered as having CNS metastases; MRI, other advanced techniques, such as positron emission tomography-computed tomography $(\mathrm{PET} / \mathrm{CT})$, and response to steroids/antiparasitic treatment helped in distinguishing NC from CNS metastases. MRI showed multiple NC lesions, and the most common finding was the vesicular stage.

Tapeworm infections have accompanied humans for more than 100,000 years. Characterization of the genomes of these parasites, as well as a deeper understanding 
of their molecular markers and the host-parasite relationship ${ }^{10}$, has improved diagnosis, treatment, and prevention. The diagnosis of $\mathrm{NC}$ is made by neuroimaging techniques, such as CT or MRI. The characteristics of NC vary according to the phases of development, including non-cystic, vesicular, colloidal vesicular, granular nodular, calcified nodular vesicular, and colloid to calcified stages. One of the known features of NC is the presence of multiple phases in the same patient ${ }^{11}$. Some have proposed a serologic test to confirm the diagnosis. The most recommended study is the enzyme-linked immunotransfer blot because of its high specificity and sensitivity in the context of active lesions. It uses purified glycoprotein antigens from T. solium in either cerebrospinal fluid (CSF) or serum samples. Enzyme-linked immunosorbent assays are better for CSF than for serum samples, but these are not fully recommended because of the poor specificity and sensitivity ${ }^{12}$. These serologic diagnostic studies are not used frequently and are not currently required for the diagnosis of $\mathrm{NC}^{13,14}$.

Some limitations should be considered in the present study. There may have been selection bias because it was done at a single cancer referral center, the studied population was high-risk, and only patients who were referred for neuro-oncologic consultation were included. To avoid information bias, all data had strict definitions, and all information was evaluated by the main author (BC). This study was not a population-based report and did not aim to review all of the MRI studies done at the institution to establish frequency.

\section{Conclusion}

In conclusion, although some have postulated that $\mathrm{NC}$ increases the risk of glioma and stroke, we consider that the relationship between NC and the development of CNS metastases is worth exploring, as the others have proposed ${ }^{15}$. In this study, none of the patients with NC developed simultaneous or asynchronous CNS metastasis. Perhaps, the excessive TH2 response seen in $\mathrm{NC}^{16}$ is responsible for that effect, in some extent. A series of certain HLA haplotypes, which have been considered to affect the susceptibility to NC infection ${ }^{17,18}$, will now be studied further at our institution. The estimated incidence of NC and cancer is not low and should be considered a differential diagnosis of brain metastases, especially in developing countries.

\section{Conflict of interests}

None to declare.

\section{Funding}

None to declare.

\section{Ethical disclosures}

Protection of human and animal subjects. बThe authors declare that the procedures followed were in accordance with the regulations of the relevant clinical research ethics committee and with those of the Code of Ethics of the World Medical Association (Declaration of Helsinki).

Confidentiality of data. The authors declare that they have followed the protocols of their work center on the publication of patient data.

Right to privacy and informed consent. The authers declare that no patient data appear in this article.

\section{References}

1. Del Brutto OH, Castillo PR, Mena IX, Freire AX. Neurocysticercosis among patients with cerebral gliomas. Arch Neurol. 1997;54:1125-8.

2. Garcia HH, Nash TE, Del Brutto $\mathrm{OH}$. Clinical symptoms, diagnosis, and treatment of neurocysticercosis. Lancet Neurol. 2014;13:1202-15.-

3. Fleury A, Gomez T, Alvarez I, Meza D, Huerta M, Chavarria A, et aPHigh prevalence of calcified silent neurocysticercosis in a rural village of Mexico. Neuroepidemiology. 2003:22:139-45.

4. Siegel RL, Miller KD, Jemal A. Cancer statistics, 2018. CA Cancer J Clin 2018;68:7-30.

5. Herrera LA, Benita-Bordes A, Sotelo J, Chávez L, Olvera J, Rascôn A, et al. Possible relationship between neurocysticercosis and hematological malignancies. Arch Med Res. 1999;30:154-8.

6. Villagran J, Olvera JE. Cisticercosis humana: estudio clínico y patológico de 481 casos de autopsias. Patología. 1988;26:149-56.

7. Del Brutto OH, Dolezal M, Castillo PR, García HH. Neurocysticercosis and oncogenesis. Arch Med Res. 2000;31:151-5.

8. Del Brutto $\mathrm{OH}$, García HH. Neurocysticercosis in nonendemic countries: time for a reappraisal. Neuroepidemiology. 2012;39:145-6.

9. Zammarchi L, Strohmeyer M, Bartalesi F, Bruno E, Muñoz J, Buonfriate D, et al. Epidemiology and management of cysticercosis and Taenia solium taeniasis in Europe, systematic review 1990-2011. PLoS One. 2013:8:e69537.

10. Bobes RJ, Fragoso G, Fleury A, García-Varela M, Sciutto E, Larralde C, et al. Evolution, molecular epidemiology and perspectives on the research of taeniid parasites with special emphasis on Taenia solium. Infect Genet Evol. 2014;23:150-60.

11. Nash TE, Garcia HH. Diagnosis and treatment of neurocysticercosis. Nat Rev Neurol. 2011;7:584-94.

12. Rodriguez S, Dorny P, Tsang VC, Pretell EJ, Brandt J, Lescano AG.et al. Detection of Taenia solium antigens and anti-T. solium antibodies in paired serum and cerebrospinal fluid samples from patients with intraparenchymal or extraparenchymal neurocysticercosis. J Infect Dis. 2009;199:1345-52.

13. Singhi P. Neurocysticercosis. Ther Adv Neurol Disord. 2011;4:67-81.

14. White AC Jr., Coyle CM, Rajshekhar V, Singh G, Hauser WA, Mohanty A, et al. Diagnosis and treatment of neurocysticercosis: 2017 clinicalpractice guidelines by the infectious diseases society of America (IDSA) and the American society of tropical medicine and hygiene (ASTMH). Am J Trop Med Hyg. 2018;98:945-66.

15. Azad R, Gupta RK, Kumar S, Pandey CM, Prasad KN, Husain N, ret al. Is neurocysticercosis a risk factor in coexistent intracranial disease? An MRI based study. J Neurol Neurosurg Psychiatry. 2003;74:359-61.

16. Chavarría A, Roger B, Fragoso G, Tapia G, Fleury A, Dumas M, et al. TH2 profile in asymptomatic Taenia solium human neurocysticercosis. Microbes Infect. 2003;5:1109-15.

17. Jain S, Padma MV, Kanga U, Mehra NK, Puri A, Maheshwari MC et al. Family studies and human leukocyte antigen class II typing in Indian probands with seizures in association with single small enhancing-computed tomography lesions. Epilepsia. 1999:40:232-8.

18. Arora N, Tripathi S, Sao R, Mondal P, Mishra A, Prasad A, et al. Tolecular neuro-pathomechanism of neurocysticercosis: how host genetic factors influence disease susceptibility. Mol Neurobiol. 2018;55:1019-25. 